\title{
Slurry Erosion Behaviour of Plasma Thermal Sprayed (50\%) WC-Co-Cr and Ni-Cr-B-Si Coatings of Different Thickness on CA6NM Turbine Steel Material
}

\author{
Harpreet Singh $^{1}$, Khushdeep Goyal ${ }^{1, *}$, Deepak Kumar Goyal ${ }^{2}$ \\ ${ }^{1}$ Department of Mechanical Engineering, Punjabi University, Patiala-147002, India \\ ${ }^{2}$ Department of Mechanical Engineering, BBSBEC, Fatehgarh Sahib, Punjab, India \\ *Corresponding Author : khushgoyal@yahoo.com
}

Copyright (C) 2014 Horizon Research Publishing All rights reserved.

\begin{abstract}
Erosive wear behaviour of hydraulic turbine material i.e. CA6NM is investigated. The samples of CA6NM steel were coated by (50\%) WC-Co-Cr and $(50 \%)$ $\mathrm{Ni}-\mathrm{Cr}-\mathrm{B}-\mathrm{Si}$ powder with plasma thermal spray technique. Erosion tests have been conducted on self-made erosion test rig which has varying factors. The comparison has been done for mass loss for coated and uncoated materials at different conditions. The study reveals that the impact velocity, slurry concentration and impact angle are most significant among various factors influencing the wear rate of these coatings. After a fix time weight loss on samples are compared. This technique helps in saving time and resources for a large number of experimental trials and successfully predicts the wear rate of the coatings both within and beyond the experimental domain. The coated samples show better results as compared to uncoated. SEM analysis gives the information about the surface topography of samples.
\end{abstract}

Keywords Erosion, Turbine Steel, Coatings, Slurry, Impact

\section{Introduction}

Silt erosion of hydro turbines is a very acute problem and leads to huge losses to the hydropower industry. It can decrease the efficiency of hydro turbines up to $5-10 \%$ [1]. Erosion is more likely to be a problem for turbine blades and nozzles in hydraulic industry which has to tolerate high speed water impingement [2]. It depends on various parameters like silt size, hardness, concentration, velocity of water etc. so, it is very difficult to find common cause and remedy for slurry erosion. Selection of materials of turbines is also a considerable area of interest to resist erosion [2-5]. Due to repair, reduced efficiency and outages in rainy monsoon seasons, Indian hydro power plants located in Himalayas operate in loss of the order of US\$ 120-150 million a year [3-5].
A number of research papers are available on slurry erosion, but research related to CA6NM (ASTM 743) steel is limited [2].CA6NM steel is common material for hydroturbines because of its good corrosion and cavitation resistance and high impact toughness [6]. Grewal et al. [2] had discussed the performance of hydropower plant which was rigorously exaggerated by the presence of sand particles in river water. Degree of degradation drastically depends on the level of operating parameters (velocity, impingement angle, concentration, particle size and shape), which was further related to erosion mechanism. They investigated the effect of some of these operating parameters on erosion mechanism by using hydro turbine steel, CA6NM (13Cr4Ni). SEM and XRD techniques were used to check the morphology and variation in martensite and austenite phases of the eroded surfaces. Chattopadhyay et al. [7] had examined that the turbine runners demonstrate an unusually high rate of wear in river water with a high silt concentration. Cast ferritic stainless steel of CA6NM type was the normal turbine runner material. The slurry erosion characteristics of stellite 6, 15 wt.\% Cr-15 wt.\% Mn stainless steel, type 316L stainless steel and CA6NM were evaluated. The different wear rates of the alloys were explained in terms of the microstructure, hardness and work-hardening rate. It is observed from the literature review that no systematic in depth studies have been found on 13/4 steels. It is important to investigate how $13 / 4$ steel behaves under different experimental conditions. These investigations could help to improve the performance of this steel. Khurana et al. [8] had studied silt erosion behavior of hydro turbines. Silt erosion has a very discriminating problem and leads to enormous fatalities to the hydropower industry. Erosive wear depends upon different parameters such as silt size, hardness and concentration, velocity of water and base material properties. In most cases, this could be diminished by scheming the above mentioned parameters, but during the Monsoon season, it becomes unfeasible to control these parameters which cause erosion. It was observed that these factors increases the wear rate, which results decrease in 
competence of turbines and finally collapse of hydraulic turbines takes place. In this study they discussed various case studies and experimental data and also discussed the some curative measures suggested by various investigators. Luyckx et al. [9] analyzed the composition and microstructure of agglomerated and sintered $\mathrm{WC}-\mathrm{VC}-\mathrm{Co}$ thermal spray powders and of the high pressure/high velocity oxy-fuel (HP/HVOF) coatings and compared to those of agglomerated and sintered commercial WC-Co thermal spray powders of equal Co mass fraction and of the commercial WC-Co coatings that were deposited under the same conditions as the WC-VC-Co coatings. In both materials, during coating deposition the $\mathrm{WC}$ grains obtain a less angular morphology and finer mean size than in the powders and a significant fraction of $\mathrm{WC}$ grains are decarburized, with the formation of $\mathrm{W}_{2} \mathrm{C}$ and $\mathrm{Co}_{6} \mathrm{~W}_{6} \mathrm{C}$. The results of the analyses showed the abrasion resistance of $\mathrm{WC}-\mathrm{VC}-\mathrm{Co}$ coatings being superior to that of $\mathrm{WC}-\mathrm{Co}$ coatings. The characterization of $\mathrm{WC}-\mathrm{VC}-\mathrm{Co}$ and $\mathrm{WC}-\mathrm{Co}$ thermal spray powders and coatings of equal Co mass fractions had led to new quantitative imminent into some of the processes occurring during coating deposition and to an explanation of the difference in abrasion resistance between $\mathrm{WC}-\mathrm{VC}-\mathrm{Co}$ and $\mathrm{WC}-\mathrm{Co}$ coatings.

Goyal et al. [10] deposited $\mathrm{WC}-10 \mathrm{Co}-4 \mathrm{Cr}$ and $\mathrm{Al}_{2} \mathrm{O}_{3}+13 \mathrm{TiO}_{2}$ coatings on $\mathrm{CF} 8 \mathrm{M}$ turbine steel by $\mathrm{HVOF}$ spray process and studied their performance under slurry erosion conditions. The bare steel and $\mathrm{Al}_{2} \mathrm{O}_{3}+13 \mathrm{TiO}_{2}$ coating showed ductile and brittle mechanisms respectively under slurry erosion, whereas the $\mathrm{WC}-10 \mathrm{Co}-4 \mathrm{Cr}$ coating exhibit mixed behavior (mainly ductile). $\mathrm{WC}-10 \mathrm{Co}-4 \mathrm{Cr}$ coating was found to be useful to increase the slurry erosion resistance of steel remarkably. Sidhu et al. [11] performed the experimental studies at $755^{\circ} \mathrm{C}$ and study was performed up to 10 cycles and each of $100 \mathrm{~h}$ duration followed by $1 \mathrm{~h}$ cooling at ambient temperature. The highest degradation resistance has been showed by the T11 steel coated and subsequently laser remelted. Plasma sprayed Stellite-6 (St-6) coating has been found to be effective in increasing the erosion-corrosion resistance of boiler steels in the coal fired boiler environment. From T22, GrA1 andT11; T11 was lesser remelted. Otsubo et al. [12] had investigated the structure, hardness, and shear adhesion strength for $\mathrm{Cr}_{3} \mathrm{C}_{2}$-NiCr cermet coatings sprayed onto a mild steel substrate by $200 \mathrm{~kW}$ high power plasma spraying (HPS) and high velocity oxy-fuel (HVOF) processes. They studied that amorphous and supersaturated nickel phases occurred in both as-sprayed coatings. Due to non melted $\mathrm{Cr}_{3} \mathrm{C}_{2}$ carbide particles, the hardness of HVOF coating was higher as compare to high power plasma spraying (HPS). On heat treating at $873 \mathrm{~K}$, the amorphous phase decomposes and precipitation of $\mathrm{Cr}_{3} \mathrm{C}_{2}$ carbides occurred which causes increase in hardness of the HPS coating. They studied that the ratio of the hardness measured with a large load to that measured with a small load could be used as an index to indicate the ductility of the coatings. The ductility and adhesion strength of the HVOF coating was higher than that of the HPS coating. The adhesion of the coatings was intensifying by heat treating at $1073 \mathrm{~K}$, and that of the HVOF coating was over $350 \mathrm{MPa}$. Stein et al. [13] used particle accelerator apparatus set at a velocity of $40 \mathrm{~m} / \mathrm{s}$, a mass flow of $80 \mathrm{~g} / \mathrm{min}$ at $400^{\circ} \mathrm{C}$ with $450 \mu \mathrm{m} \mathrm{Al}_{2} \mathrm{O}_{3}$ particles at $30^{\circ}$ and $90^{\circ}$ impact angles for erosion testing. As a result of spraying, a wide range of $\mathrm{Cr}$ and $\mathrm{Fe}$ oxides were produced. Specifically maghemite, a synthetic iron oxide formed in the presence of $\mathrm{CO}$, was found in the final coatings. Image analysis revealed the carbide levels in the pre-sprayed powder are much higher than in the final as sprayed coating. Coating compositions reveals that with these spray parameters, the retention of the $\mathrm{Fe}-\mathrm{Cr}-\mathrm{Al}-\mathrm{Y}$ and $\mathrm{NiCr}$ matrix is better than that of chromium carbide. Researcher found that in these sprayed coatings the decrease in the carbide content, and overall hard phase content (oxides and carbides), decreased the erosion rate for $90^{\circ}$ impact. In addition, for $30^{\circ}$ impact the erosion rate remained fairly constant despite of carbide or hard phase content. Rajasekaran et al. [14] had performed uniaxial plain fatigue and fretting fatigue test on detonation gun sprayed $\mathrm{Cu}-\mathrm{Ni}-\mathrm{In}$ coating on $\mathrm{Al}-\mathrm{Mg}-\mathrm{Si}$ alloy samples. The samples in three conditions were considered: uncoated, as coated and ground after coating. Ground coated specimens exhibited superior plain fatigue and fretting fatigue lives compared with uncoated and as-coated specimens. The life enrichment has been discussed in terms of surface finish and residual compressive stresses at the surface.

Literature review reveals that no systematic in depth studies have been found on CA6NM steels. It is important to investigate how CA6NM steel behaves under different experimental conditions. These investigations could help to improve the performance of this steel in real working environments.

\section{Experimentation}

\section{Material}

The detailed composition of material used i.e. CA6NM was checked at Munjal Castings, Ludhiana (Punjab, India). The composition of material is given in table 1 . The dimension of the samples was taken as $50 \times 30 \times 10 \mathrm{~mm}$.

Table 1. Composition of CA6NM steel

\begin{tabular}{|c|c|c|c|c|c|c|c|c|c|c|c|}
\hline Element & $\mathrm{C}$ & $\mathrm{Si}$ & $\mathrm{Mn}$ & $\mathrm{P}$ & $\mathrm{S}$ & $\mathrm{Cr}$ & $\mathrm{Mo}$ & $\mathrm{Ni}$ & $\mathrm{Co}$ & $\mathrm{V}$ & $\mathrm{Fe}$ \\
\hline $\begin{array}{c}\text { Percentage } \\
(\%)\end{array}$ & 0.030 & 0.639 & 0.166 & 0.021 & 0.004 & 12.92 & 0.594 & 3.05 & 0.055 & 0.006 & 82.41 \\
\hline
\end{tabular}


The Plasma thermal spray technique has been used for coating .The coating of $50 \%$ (WC-Co-Cr) and $50 \%$ (Ni-Cr-B-Si) powder was done on the specimens. Both sides of the samples were used and coating of 250 and 400 micron was done. $50 \%$ (WC-Co-Cr) and 50\% (Ni-Cr-B-Si) coating of $250 \mu \mathrm{m}$ thickness is named as coating A and coating of $400 \mu \mathrm{m}$ thickness is named as coating B.

\section{Test Apparatus}

The jet type erosion testing rig machine was made at Punjabi University, Patiala. The test rig shown in figure 1 consists of a centrifugal pump, conical tank, nozzle, specimen holder, valves and flow meter. Centrifugal pump driven by $5 \mathrm{HP}, 1500 \mathrm{rpm}$ electric motor has a capacity of max pressure $13.5 \mathrm{bar}$ at a discharge of $240 \mathrm{l} / \mathrm{min}$. Slurry available is sucked through a $100 \mathrm{~mm}$ GI pipe with help of pump and delivered to the nozzle through $25 \mathrm{~mm}$ pipe having control valves. Slurry is re-circulated during test. During test the temperature of slurry increase to a certain level and thereafter remains constant, which is due to mechanical action of pump. The flow rate of the slurry is controlled with help of main valve and bypass regulator valve between delivery side and nozzle. The rectangular tapered tank having $600 \times 450 \mathrm{~mm}$ at top which converges to $100 \times 100 \mathrm{~mm}$ at the bottom through a length of $1200 \mathrm{~mm}$ was used to store the slurry.

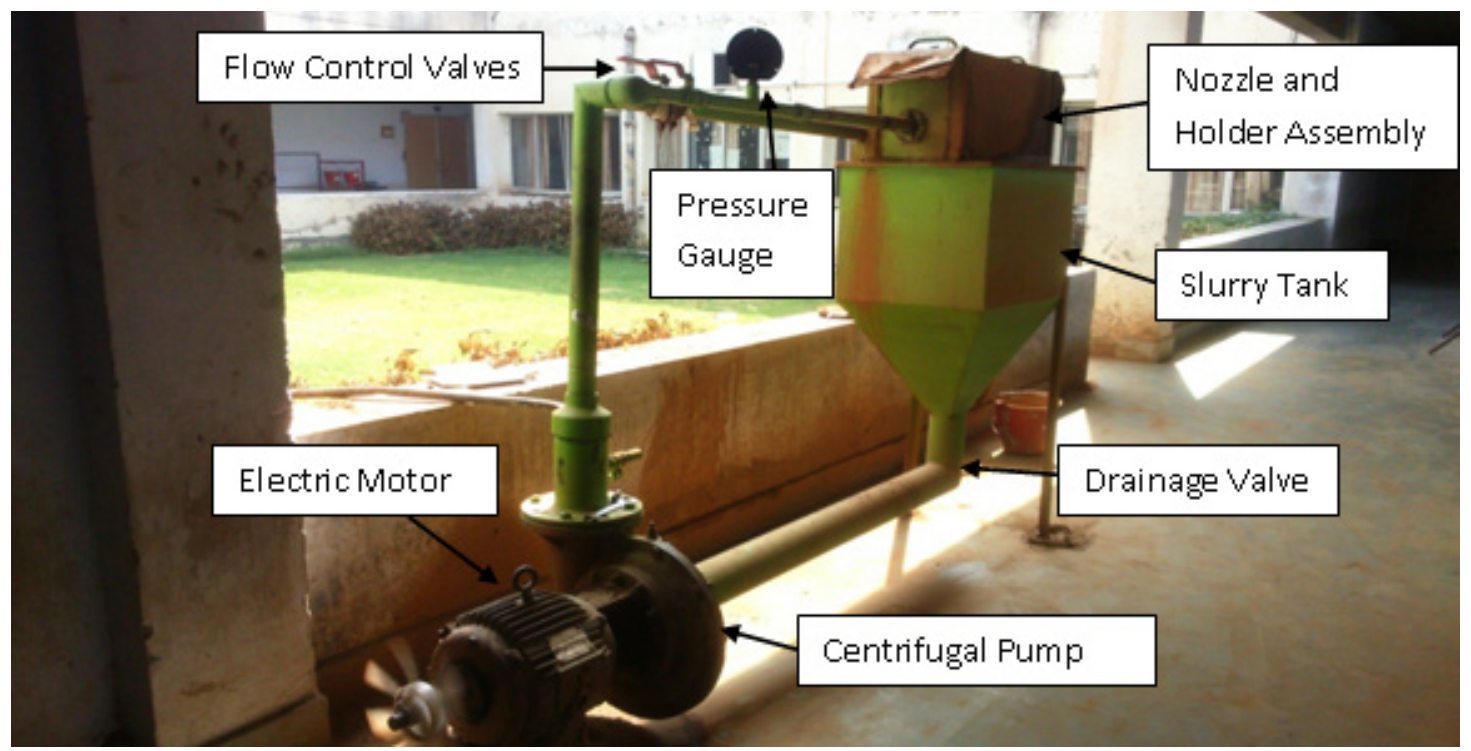

Figure 1. Jet Erosion Tester

\section{Experimental Design}

Table 2 shows the design of $\mathrm{L}_{9}$ orthogonal array and Table 3 shows different levels of different parameters.

Table 2. $\mathrm{L}_{9}$ orthogonal array of Taguchi Method for experimentation design

\begin{tabular}{|c|c|c|c|c|}
\hline Various Runs & Particle size & Concentration & Velocity & Impact Angle \\
\hline Run 1 & A1 & B1 & D1 \\
\hline Run 2 & A1 & B2 & C2 \\
\hline Run 3 & A1 & B3 & D3 \\
\hline Run 4 & A2 & B1 & D3 \\
\hline Run 5 & A2 & B2 & C1 & D1 \\
\hline Run 6 & A2 & B3 & C3 & D2 \\
\hline Run 7 & A3 & B1 & C1 & D3 \\
\hline Run 8 & A3 & B3 & C2 & D1 \\
\hline Run 9 & & B & D & D \\
\hline
\end{tabular}


Table 3. Different values of parameters

\begin{tabular}{|c|c|c|c|c|c|c|c|}
\hline \multicolumn{2}{|c|}{ Particle Size (in $\mu \mathrm{m})$} & \multicolumn{2}{|c|}{ Concentration (in ppm) } & \multicolumn{2}{|c|}{ Velocity (in $\mathrm{m} / \mathrm{sec}$ ) } & \multicolumn{2}{|c|}{ Impact Angle (in degrees) } \\
\hline $\mathrm{A} 1$ & 150 & B1 & 10,000 & $\mathrm{C} 1$ & 20 & D1 & 30 \\
\hline A2 & 250 & B2 & 20,000 & $\mathrm{C} 2$ & 40 & D2 & 60 \\
\hline A3 & 350 & B3 & 30,000 & $\mathrm{C} 3$ & 60 & D3 & 90 \\
\hline
\end{tabular}

\section{Results and Discussion}

\subsection{Erosion Performance}

Erosion Performance of $50 \%$ (WC-Co-Cr) and (50\%) Ni-Cr-B-Si coating of $250 \mu \mathrm{m}$ thickness at different experimental runs

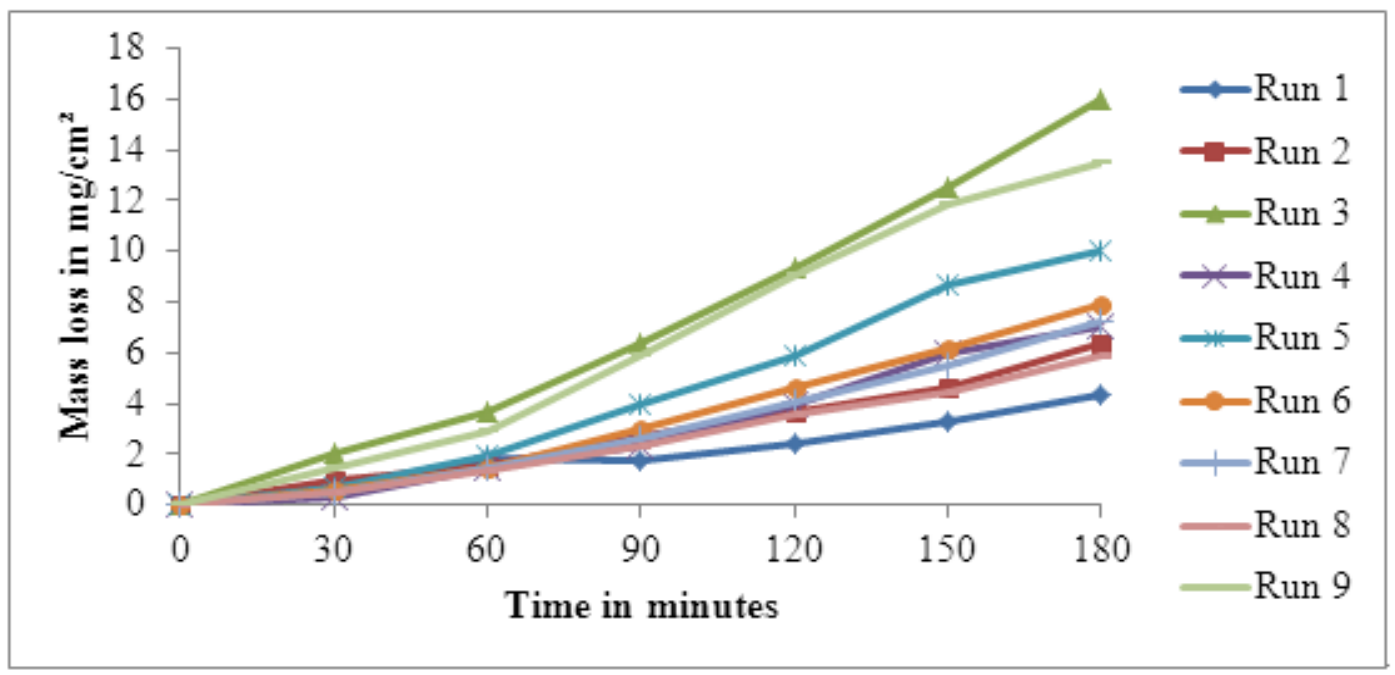

Figure 2. Variation in mass loss w. r. t. time for coating A at different runs

Figure 2 shows that the erosion of coating A is maximum at run 3, where angle of impingement is $90^{\circ}$,velocity $60 \mathrm{~m} / \mathrm{s}$ and maximum concentration level and erosion is minimum at run 1, where angle is 30 and concentration and velocity levels are minimum. For run 4 and run 5, there is no much difference in mass loss.

Erosion Performance of 50\% (WC-Co-Cr) and (50\%) Ni-Cr-B-Si coating of $400 \mu \mathrm{m}$ thickness coating at different runs

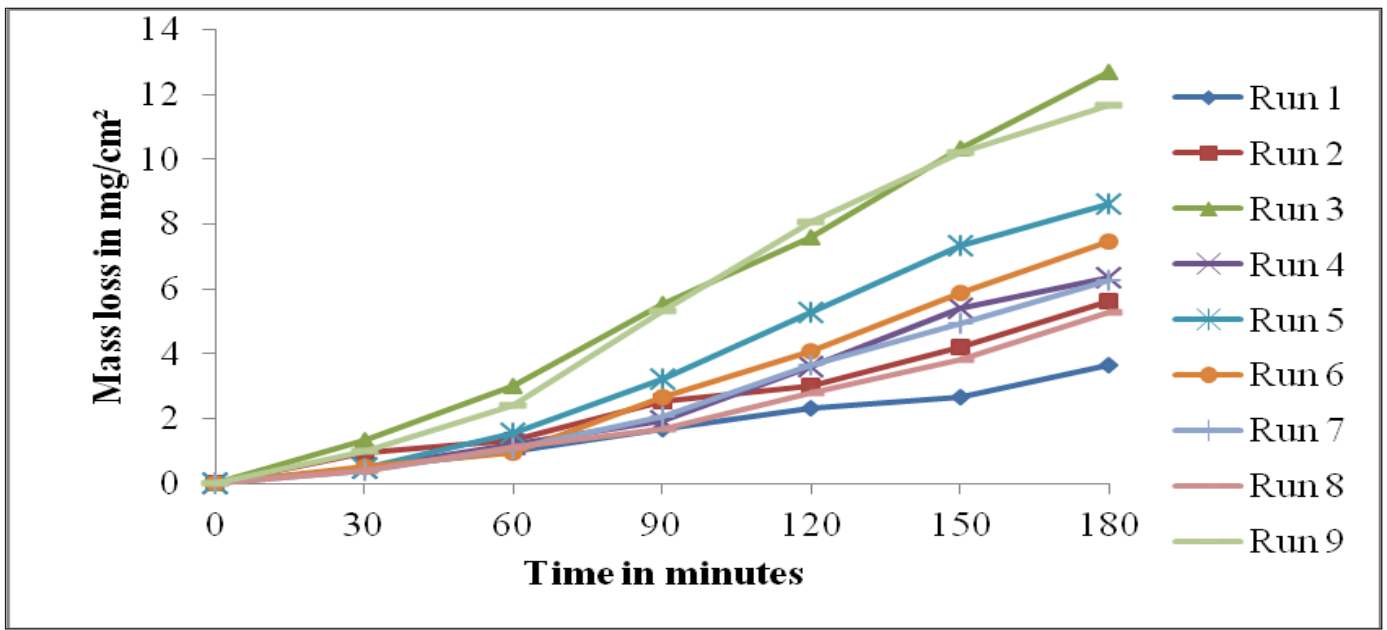

Figure 3. Variation in mass loss w. r. t. time for coating B at different runs 
Figure 3 shows the erosion rate at different runs for coating B. The erosion is maximum for run 3 at angle of $90^{\circ}, 60 \mathrm{~m} / \mathrm{s}$ velocity, maximum concentration and minimum particle size. The erosion for run 1 is minimum at $30^{\circ}$ angle, minimum velocity, minimum particle size and concentration level. For run 5 and 4 there are almost similar erosion rates.

\section{Erosion Performance of uncoated CA6NM steel at various runs}

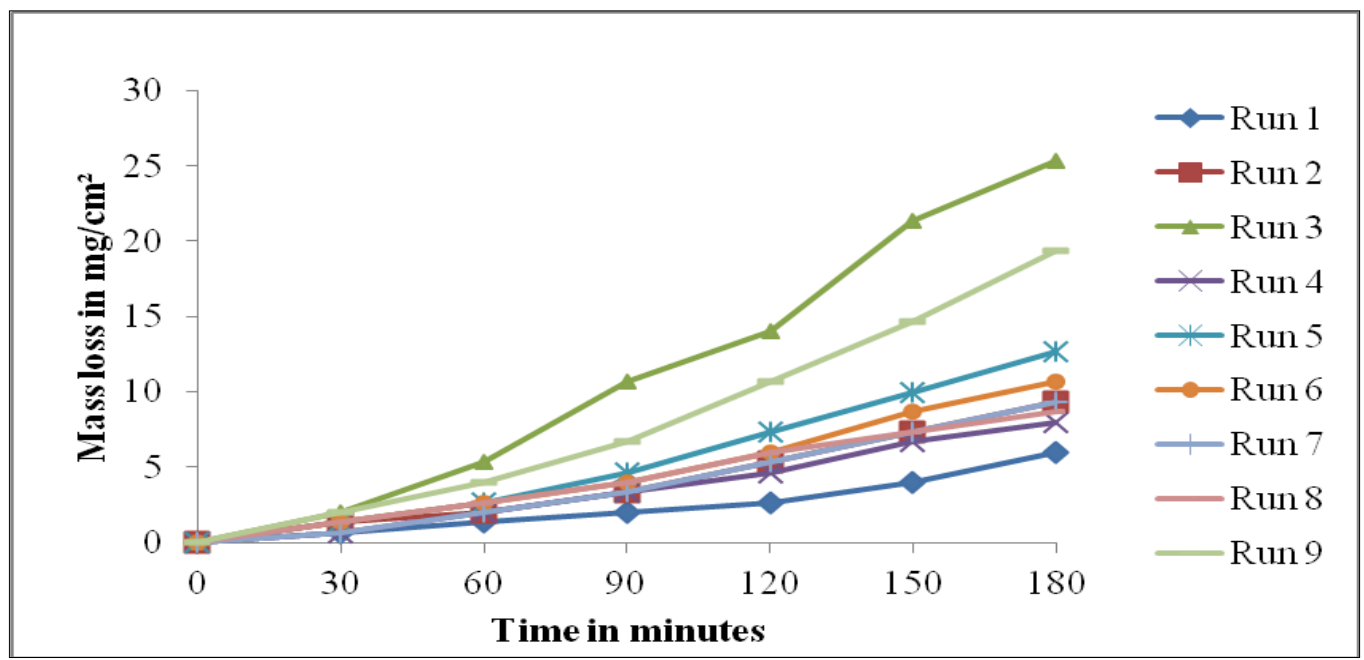

Figure 4. Variation in mass loss w. r. t. time for uncoated samples at different runs

Figure 4shows the erosion rate for different runs for the uncoated CA6NM steel. The erosion rate is maximum for run 3 and minimum for the run 1.The angle in run 3 is $90^{\circ}$, concentration and velocity is maximum while particle size is minimum. The erosion rate is similar for run 7 and 2 , in these both similar concentrations is used, while angle is $60^{\circ}$ and $30^{\circ}$ respectively. After one hour the difference in erosion rate is more significant for different runs.

\subsection{Effect of Various Parameters}

Mass Loss Comparison of CA6NM Steel and 50\% (WC-Co-Cr) and (50\%) Ni-Cr-B-Si coating of $250 \mu \mathrm{m}$ and400 $\mu \mathrm{m}$ thickness at different runs

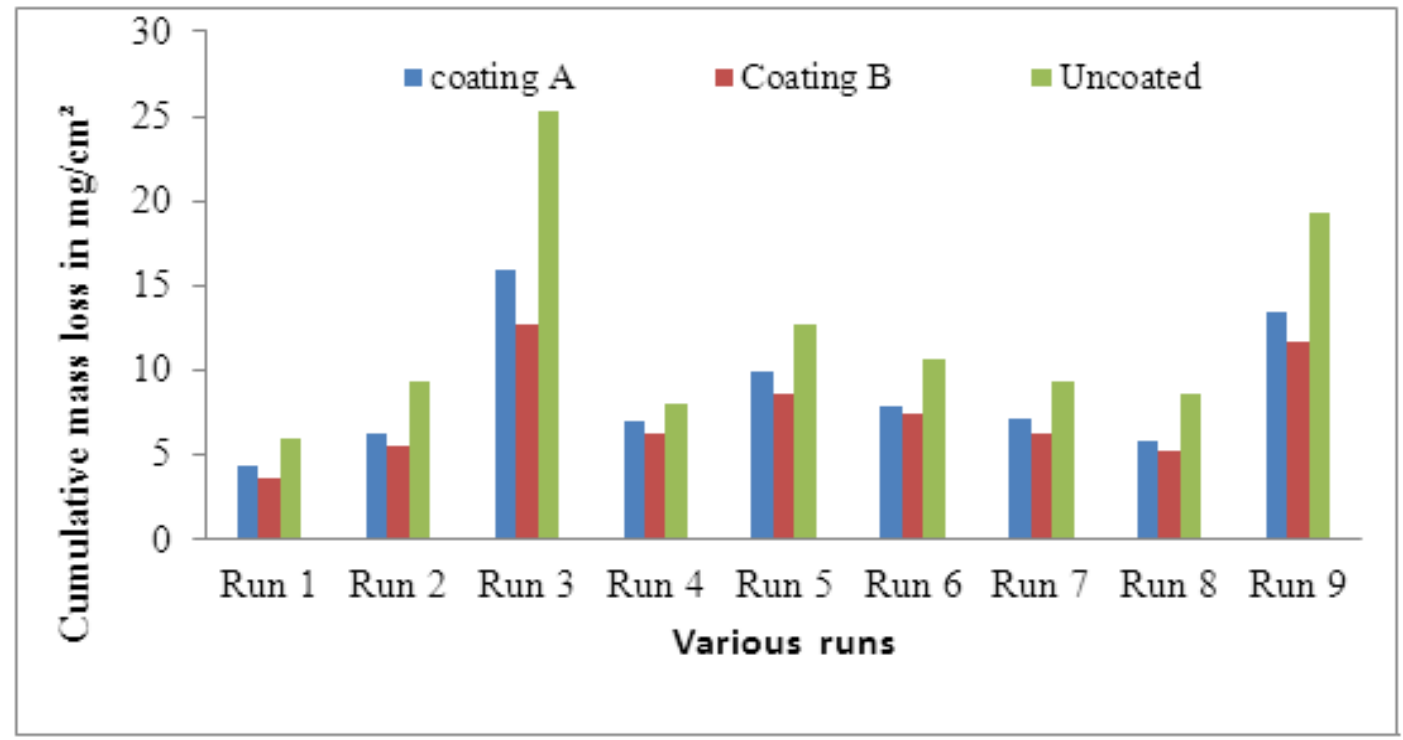

Figure 5. Cumulative mass loss w. r. t. time for different coatings at different runs

Figure 5 shows the comparison of cumulative mass loss for CA6NM steel and coatings for different runs. The mass loss for uncoated material is more at every run as compared to coatings. In run 3, the material lost of uncoated is almost double as compared to coating B. In run 4 , the difference in mass lost for coating A and B is very less. This is because the jet strikes at $90^{\circ}$ and at this angle the force exerted by jet is maximum. 


\section{Effect of concentration on Erosion Wear}

The figure 6 shows the mass loss increases with the increase in concentration. Coated and uncoated material shows that with increase in concentration the erosion rate is directly affected. The mass loss for uncoated material is maximum at the maximum concentration level. It is also maximum for coating A and coating B at maximum level of slurry concentration. The mass loss at $30000 \mathrm{ppm}$ is almost double as compared to $10000 \mathrm{ppm}$ concentration.

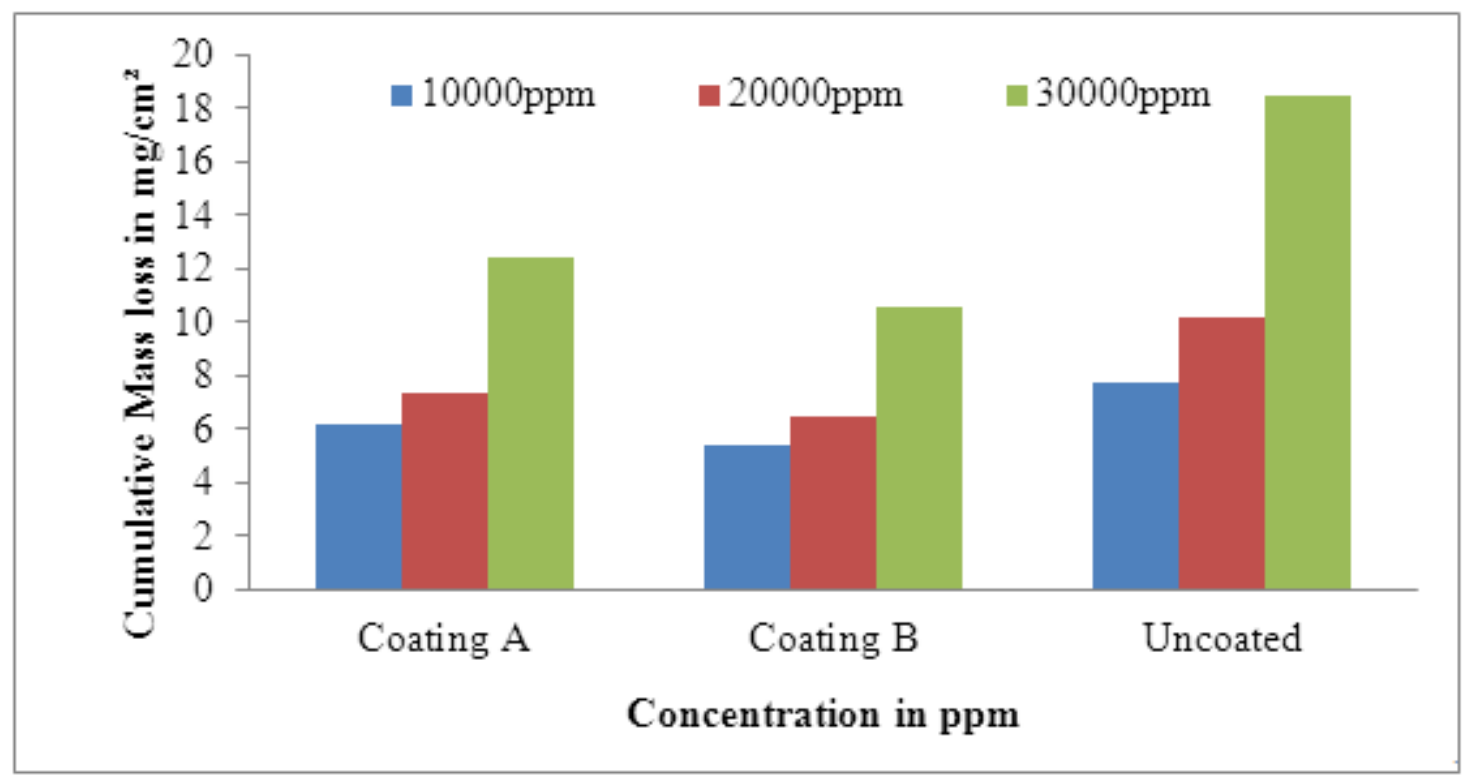

Figure 6. Comparison of cumulative mass loss at different concentrations

\section{Effect of Velocity on Erosion Wear}

The effect of velocity on erosion wear is shown in figure 7.

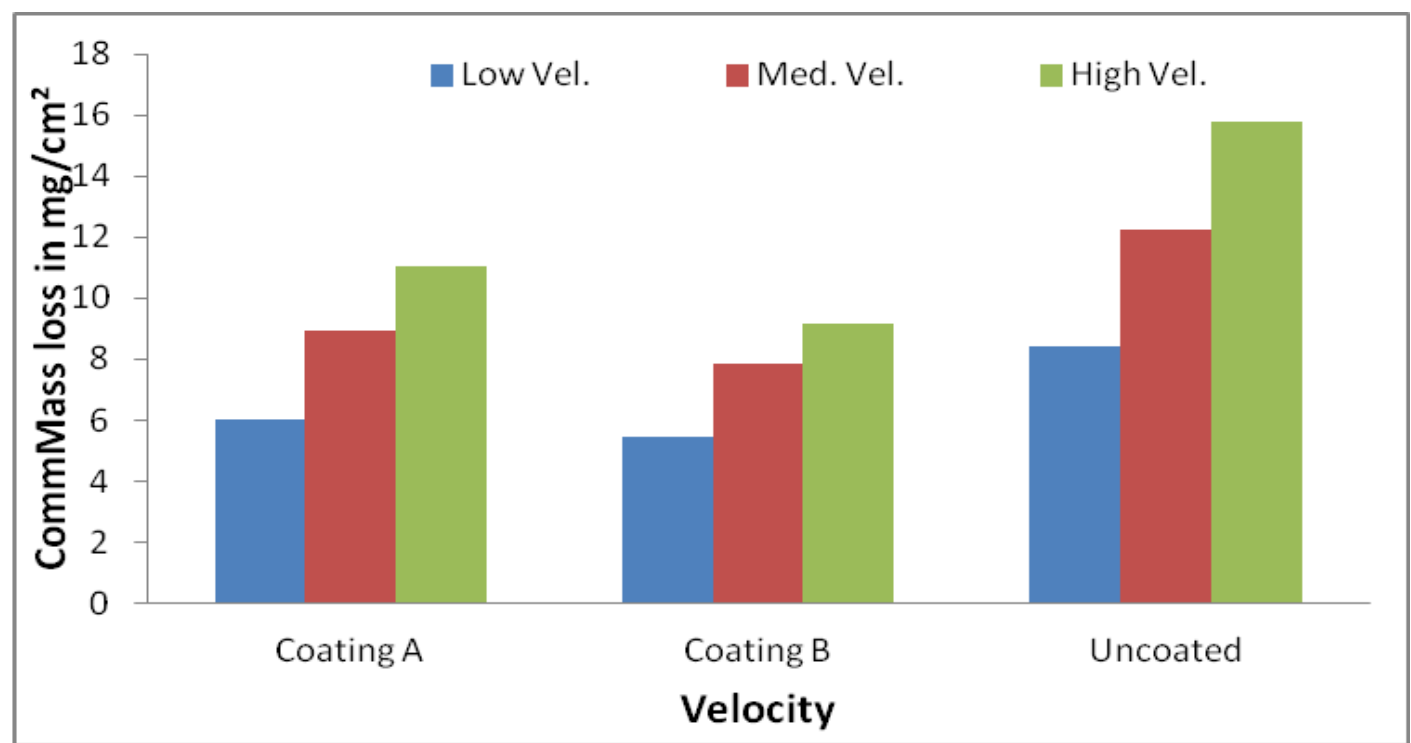

Figure 7. Comparison of cumulative mass loss at different levels of velocity

It is clear from figure 7 that loss of material increases with increase in velocity at different angles. A rise in weight loss is approximately $45 \%$ when velocity is increased from $20 \mathrm{~m} / \mathrm{s}$ to $60 \mathrm{~m} / \mathrm{s}$. The erosion of coating B is less as compared to coating $A$ and uncoated material. The mass loss increases with increase in velocity in CA6NM uncoated and coated material. The erosion rate increases with increase in velocity of impacting particles. These findings are similar to as reported by many researchers $[2,10]$. 


\section{Effect of Angle on Erosion Wear}

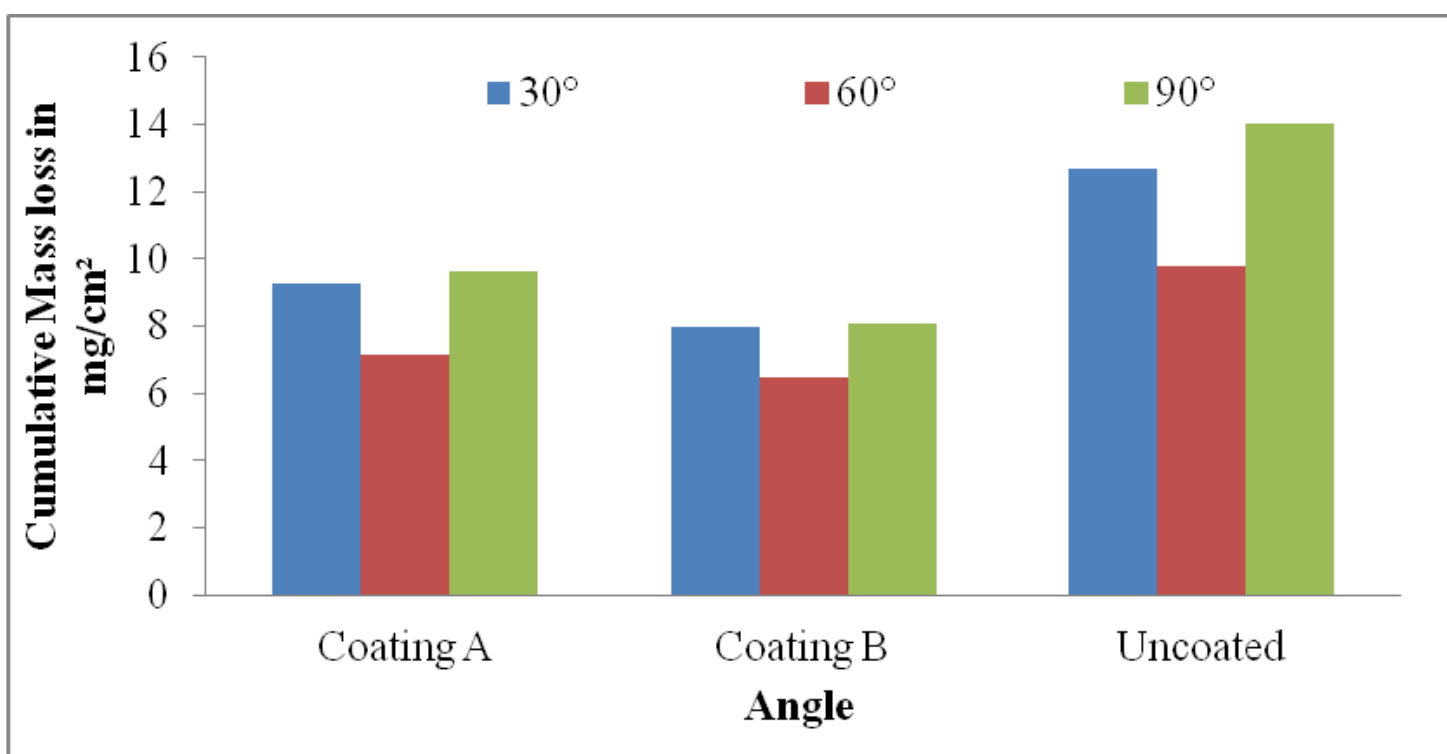

Figure 8. Comparison of cumulative mass loss at different angle

Maximum erosion occurs at $90^{\circ}$ and minimum at $60^{\circ}$ as shown in figure 8 . Higher erosion at $90^{\circ}$ indicates the CA6NM steel is ductile in nature. At $90^{\circ}$ impingement angle platelet mechanism and formation of deep craters accelerates erosion, whereas at $30^{\circ}$ angle ploughing and cutting may be responsible for removal of material [2]. Goyal et al. [10] suggested that material removal from the surface of ductile materials occurs by a process of plastic deformation, followed by cutting.

\section{Effect of particle size on Erosion Wear}

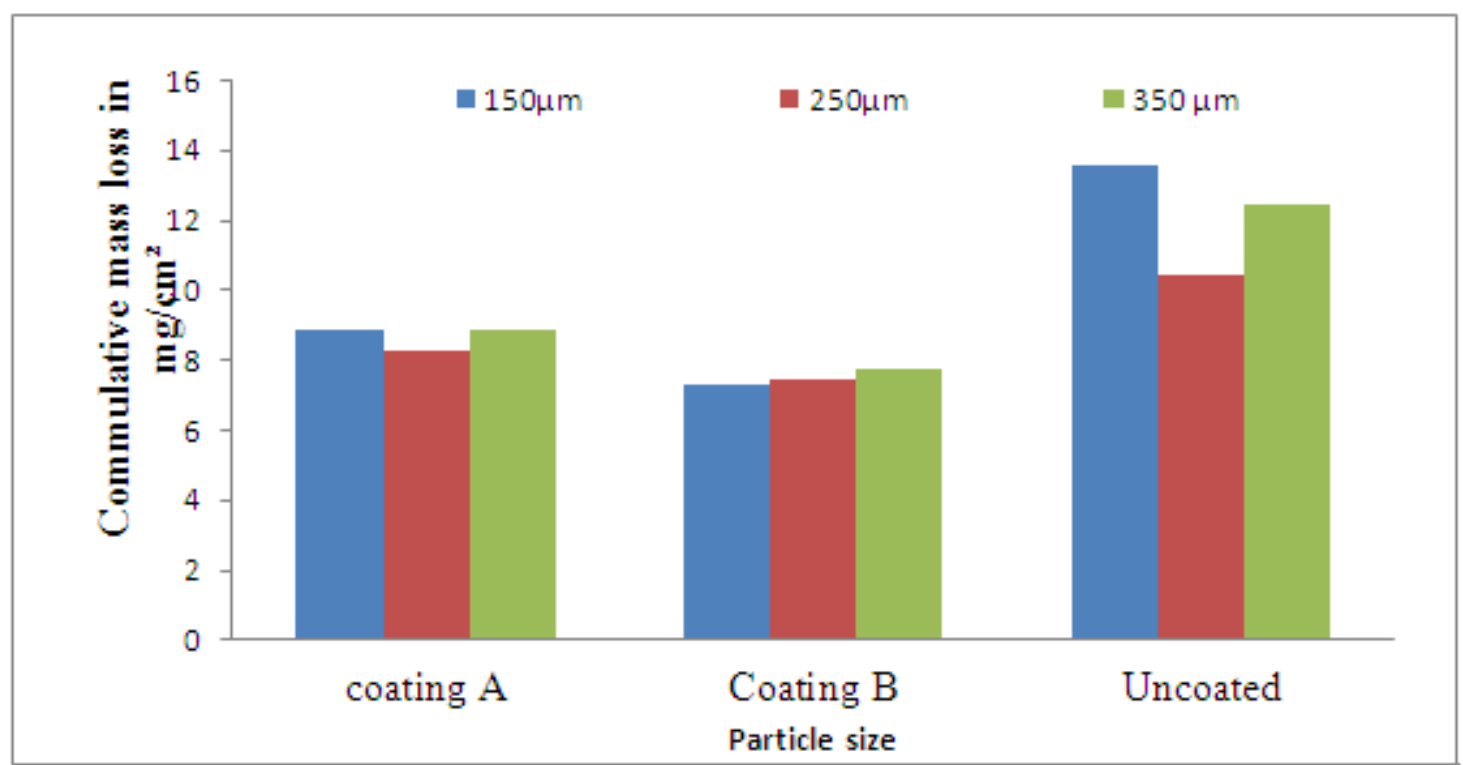

Figure 9. Comparison of cumulative mass loss at different particle size

The figure 9 shows that particle size has no significant effect on erosion rate. The mass loss in $150 \mu \mathrm{m}$ particle size is slightly high as compared to $250 \mu \mathrm{m}$ and $350 \mu \mathrm{m}$ particle size. With increase in particle size there is increase in the surface area of particle. Larger particles may restrict the other particles to come in contact with the surface. Therefore, erosion rate does not significantly change even though the mass and size of particle is greater.

\subsection{SEM Analysis}


SEM Analysis of unperformed uncoated CA6NM steel and (50\%) WC-Co-Cr and (50\%) Ni-Cr-B-Si coating of $250 \mu \mathrm{m}$ and $400 \mu \mathrm{m}$ thickness
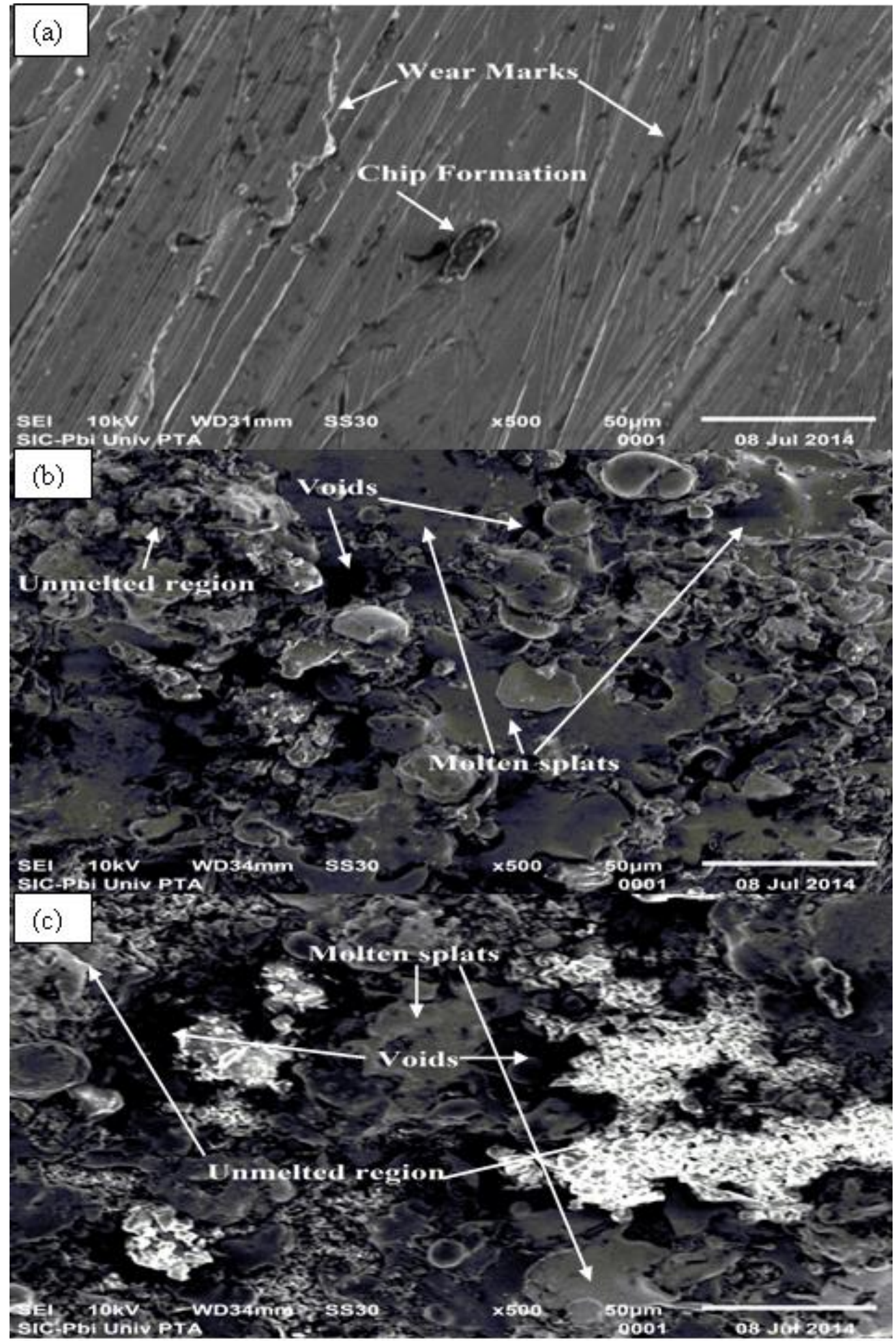

Figure 10. SEM micrograph of unperformed (a) uncoated CA6NM material (b) (50\%) WC-Co-Cr and (50\%) Ni-Cr-B-Si coating of $250 \mu \mathrm{m}$ thickness and (c) of $400 \mu \mathrm{m}$ thickness

The figure 10 shows the SEM micrograph of uncoated CA6NM , (50\%) WC-Co-Cr and (50\%) Ni-Cr-B-Si coatings of $250 \mu \mathrm{m}$ thickness and of $400 \mu \mathrm{m}$ thickness. The micrograph 10 (a) shows that in uncoated material, there is chip formation and wear marks present in the material. The coating of $250 \mu \mathrm{m}$ thickness shows that there are voids, molten splats and unmelted region. It may be due to high temperature at the time of coating deposition. The SEM micrograph 10 (c) shows that there is 
less number of voids in the surface. It may be due to grinding with the very fine emery papers. The coating has a lamellar microstructure. It also contains unmelted particles within splats. The presence of unmelted and partially melted particles in (50\%) WC-Co-Cr and (50\%) Ni-Cr-B-Si coating deposited by plasma spray process may be due to high temperatures associated with plasma spray process. The coating had a nearly uniform surface micro-structure.

\section{SEM Analysis of (50\%) WC-Co-Cr and (50\%) Ni-Cr-B-Si coating of $250 \mu \mathrm{m}$ thickness}

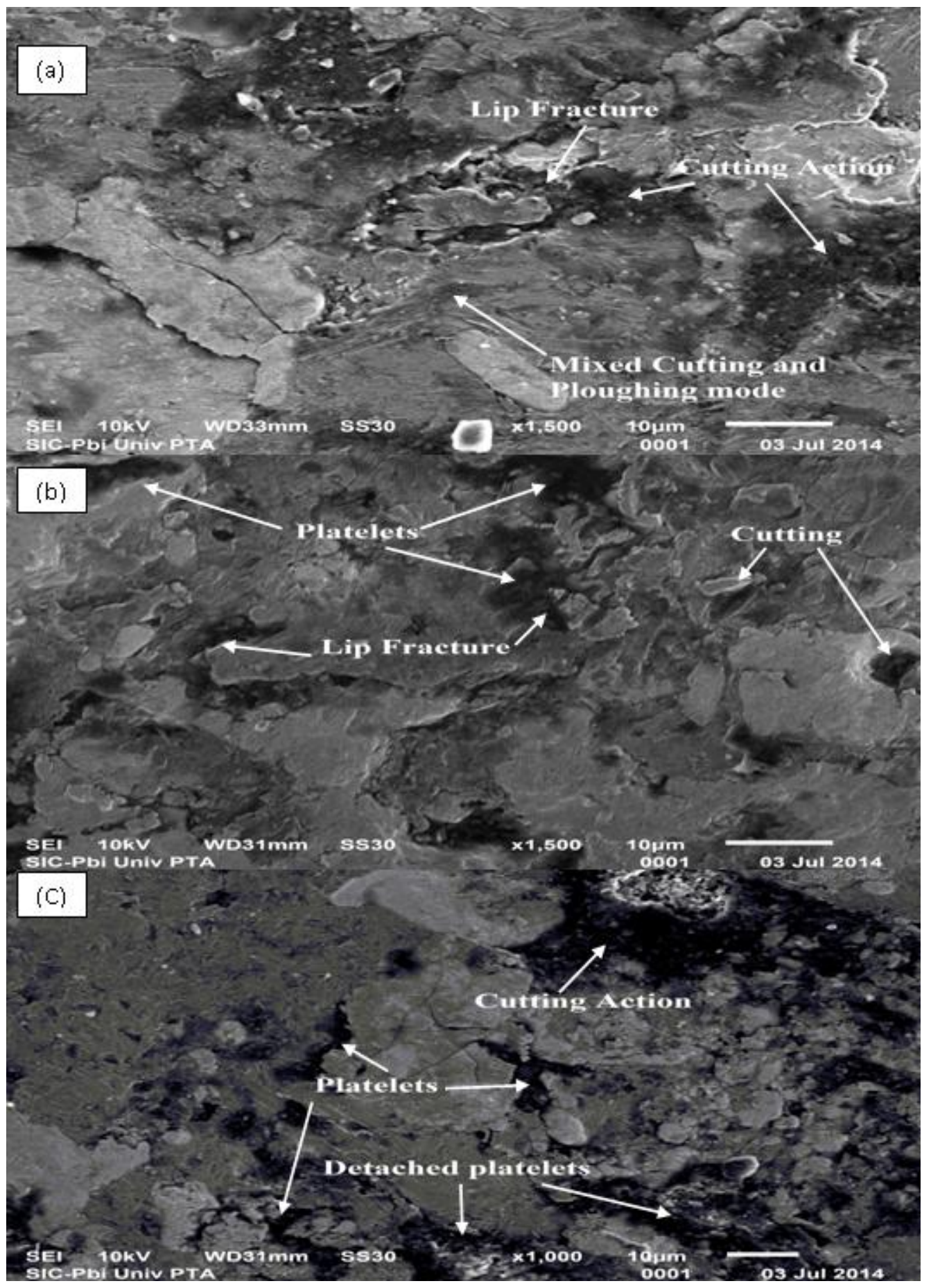

Figure 11. SEM micrograph of (50\%) WC-Co-Cr and (50\%) Ni-Cr-B-Si coating of $250 \mu \mathrm{m}$ thickness at levels of particle size, concentration, velocity and angle at (a) A1, B1,C1 and D1, (b) A2, B3, C1 and D2),(c)A2, B3, C3 and D3

Figure 11 shows the SEM micrograph of 250 micron coating at $30^{\circ}, 60^{\circ}$ and $90^{\circ}$ respectively, and particle size of 150,250 and $350 \mu \mathrm{m}$ respectively. The velocity is low, medium and high respectively in these three runs. Material removal occurs due to repetitive plastic deformation and cutting. At low impact angle, material removal is due to chip formation. Erosion at $90^{\circ}$ 
angle is due to formation of crater lips. In actual operating environment, the silt particles impinges at various impact angles over the surface of turbine components [10].There is more wear at maximum velocity, concentration and at $90^{\circ}$ angle.

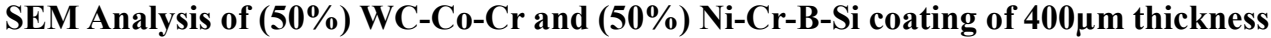

Figure 12 shows the SEM micrograph of 400 micron coating at $30^{\circ}, 60^{\circ}$ and $90^{\circ}$ respectively, and particle size of 150,250 and $350 \mu \mathrm{m}$ respectively. At $30^{\circ}$ wear marks and platelets are more than at $60^{\circ}$. While the craters and platelets are formed at the $90^{\circ}$ angle at maximum levels of velocity and concentration and shows more wear.

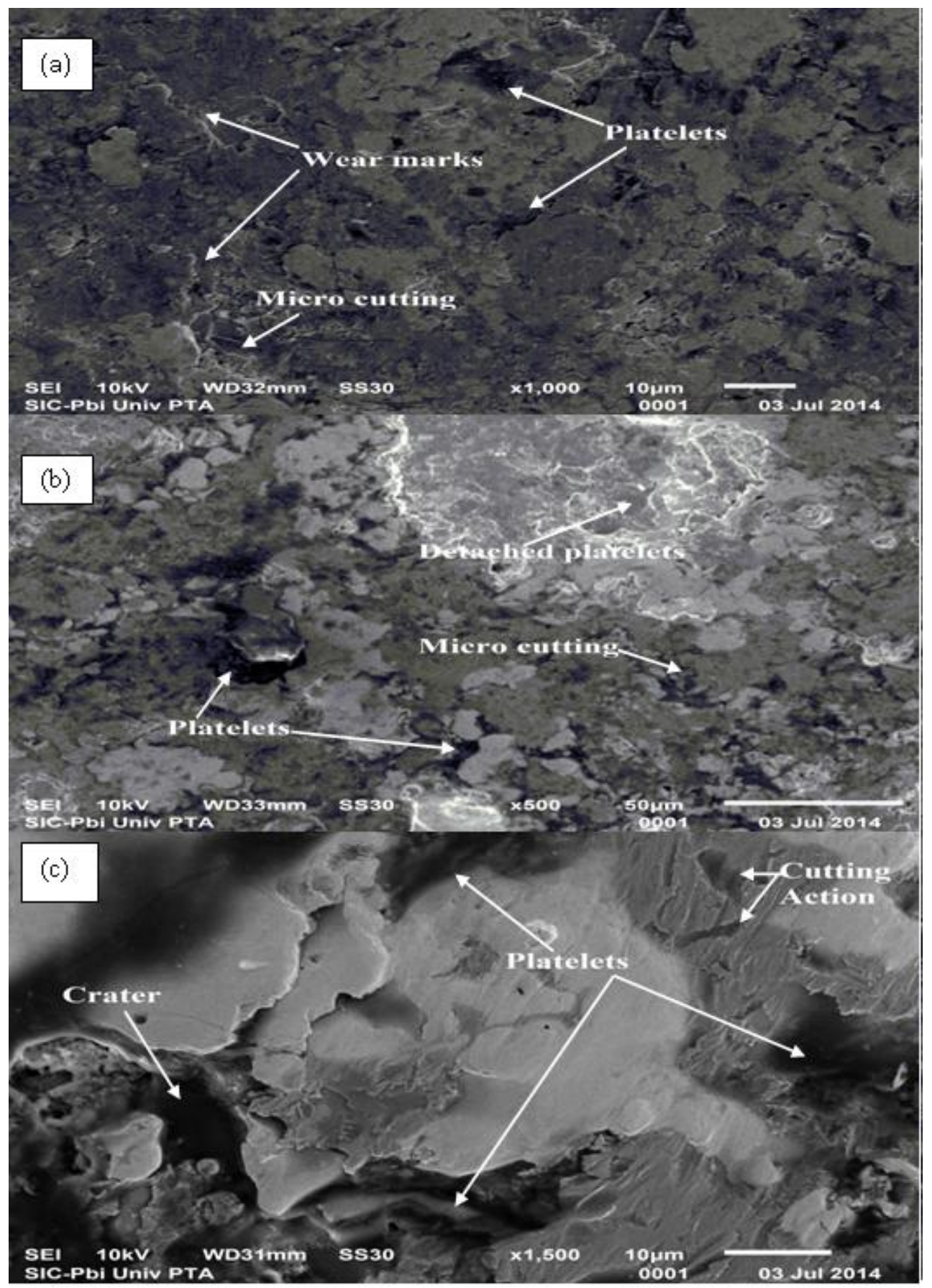

Figure 12. SEM micrograph of (50\%) WC-Co-Cr and (50\%) Ni-Cr-B-Si coating of $400 \mu \mathrm{m}$ thickness at levels of particle size, concentration, velocity and angle at (a) A1, B1,C1 and D1, (b) A2, B3 , C1 and D2),(c)A2, B3, C3 and D3 


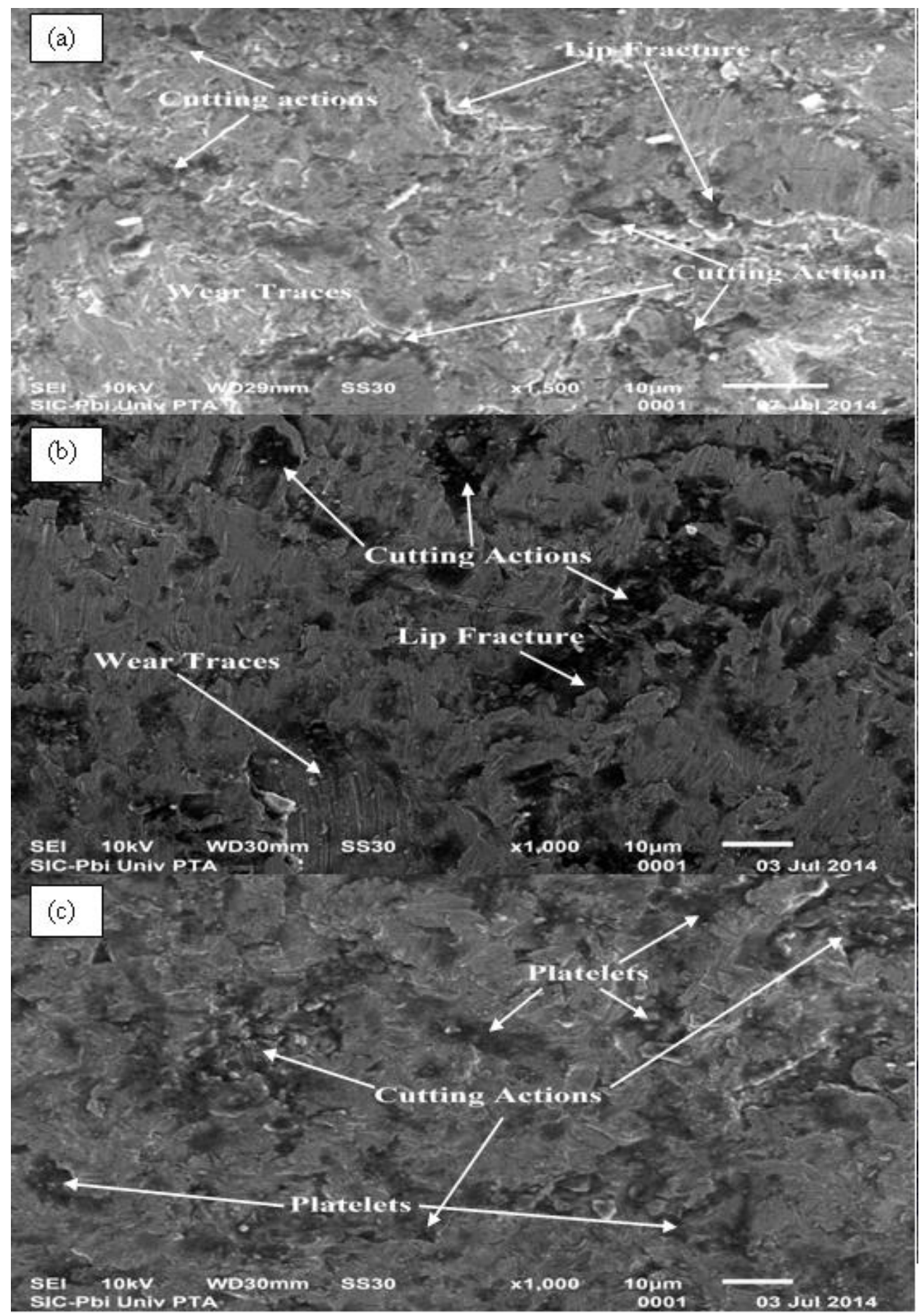

Figure 13. SEM micrograph of uncoated CA6NM at different levels of particle size, concentration, velocity and angle at (a) A1, B1,C1 and D1, (b) A2, $\mathrm{B} 3, \mathrm{C} 1$ and $\mathrm{D} 2)$ and (c)A2, B3, C3 and D3

The figure 13 shows the SEM micrograph of uncoated CA6NM steel eroded at different conditions of impacting angle, concentration, particle size and velocity. It can be observed that increase in average size of particles from $150 \mathrm{~mm}$ to $350 \mathrm{~mm}$ has resulted in formation of deeper craters on the steel surface. Also the increase in slurry concentration from10,000ppm to $30,000 \mathrm{ppm}$ might have lead to formation of more number of platelets and craters. In this case, the mechanism for material removal looks to be repetitive plastic deformation followed by cutting [10]. 


\section{Conclusions}

The effect of various parameters on slurry erosion mechanism of uncoated and coated CA6NM steel was investigated. The important conclusions drawn from the investigation are:

- The comparisons of mass loss show that erosion rate of CA6NM steel is more than coating A and coating B.

- Erosion resistance of 400 micron coating grinded with $4 / 0$ grit and 800 mesh emery papers found better as compared to 250 micron thickness coating.

- Coatings show better performance than uncoated steel in all conditions in which test was performed.

- Both the coatings show higher erosion resistance as compared to uncoated material.

- Coating A shows approximately 40 times better performance than CA6NM uncoated steel and coating B shows 57 times better performance than uncoated material.

- For CA6NM uncoated steel maximum erosion is at $90^{\circ}$ impact angle and minimum at $60^{\circ}$.

- Both coatings has maximum erosion at $90^{\circ}$.

- The SEM analysis shows that erosion mechanism of CA6NM steel under normal impact is platelet mechanism but for coating under similar condition is due to crack formation.

- For CA6NM steels the maximum erosion occurs at $90^{\circ}$ with a velocity of $60 \mathrm{~m} / \mathrm{s}$ and it is followed by erosion at $30^{\circ}$ with same velocity.

- With increased in concentration of the particles the mass loss increased for CA6NM uncoated steel.

- With increase in concentration, there is increase in the erosion rate.

- The particle size has no significant on erosion wear in uncoated and coated materials.

- For uncoated CA6NM steel, the higher erosion is caused due to impact angle

- For coated CA6NM, the higher erosion is caused due to increase in velocity.

\section{REFERENCES}

[1] Humphrey, J.A.C., " Fundamentals of fluid motion in erosion by solid particle impact",Int. J. Heat and Fluid Flow 11(3), 170-195 (1990)

[2] H.S. Grewal, A. Agrawal and H. Singh, "Slurry erosion mechanism of hydroturbine steel: Effect of operating parameters", 2013, Tribology Letter, 52,287-303.

[3] S. Khurana, K. Kumar, Varun and A. Kumar, "Silt erosion in hydro turbines - A review", 2012, International Journal of Mechanical and Production Engineering, 1(1), 34-38.

[4] D.K. Goyal, H. Singh and H. Kumar, "An overview of slurry erosion control by the application of high velocity oxy fuel sprayed coatings" 2011, Journal of Engineering Tribology, $225,1092-1105$.

[5] L. Kumar, C. Parashar and S. Kaur, 'Prediction of silt erosion in hydraulic turbine using non linear regression model”, 2013, International Journal of Engineering Sciences Research, 4(9299), 963-970.

[6] Iwabuchi, Y., Sawada, S.: Metallurgical characteristics of a large hydraulic runner casting of type $13 \mathrm{Cr}-\mathrm{Ni}$ stainless Steel. In: 1982, pp. 332-354. ASTM.

[7] R. Chattopadhyay, "High silt wear of hydro turbine runners", 1993, Wear,162-164, 1040-1044.

[8] S. Khurana, K. Kumar, V. kumar and A. Kumar, "Silt erosion in hydro turbines- A review", 2012, International Journal of Mechanical and Production Engineering,2315-4489(I), 34-38.

[9] S. Luyckx and C.N. Machio, "Characterization of WC-VCCo thermal spray powders and coatings", 2007, International Journal of Refractory Metals \& Hard Materials, 25, 11-15.

[10] D.K. Goyal, H. Singh, H. Kumar and V. Sahni, "Slurry erosion behavior of $\mathrm{HVOF}$ sprayed $\mathrm{WC}-10 \mathrm{Co}-4 \mathrm{Cr}$ and $\mathrm{Al}_{2} \mathrm{O}_{3}$ and $13 \mathrm{TiO}_{2}$ coatings on a turbine steel", 2012, Wear, 289, 46-57.

[11] B.S. Sidhu and S. Prakash "Erosion-corrosion of plasma as sprayed and laser remelted Stellite- 6 coatings in a coal fired boiler", 2006, Wear, 260, 1035-1044.

[12] F. Otsubo, H. Era, T. Uchida and K. Kishitake," Properties of $\mathrm{Cr}_{3} \mathrm{C}_{2}$-NiCr Cermet Coating Sprayed by High Power Plasma and High Velocity Oxy-Fuel Processes", 2000, Journal of Thermal Spray Technology, 59, 499-504.

[13] K.J. Stein, B.S. Schorr and A.R. Marder," Erosion of thermal spray MCr-Cr -C cermet coatings”, 1999, Wear, 224,153159.

[14] B. Rajasekaran , S.G.S Raman , S.V. Joshiand G. Sundararajan, "Effect of grinding on plain fatigue and fretting fatigue behaviour of detonation gun sprayed $\mathrm{Cu}-\mathrm{Ni}-\mathrm{In}$ coating on Al-Mg-Si alloy", 2008, International Journal of Fatigue. 